\title{
Effect of timing cord clamping on a vaginally delivered infant of a primigravida in terms of the incidence of hyperbilirubinemia
}

\author{
Maria Magdalena Setyaningsih ${ }^{1)}$, Wisoedhanie Widi Anugrahanti ${ }^{2)}$ \\ ${ }^{1,2}$ Lecture, Panti Waluya Malang Nursing Academy \\ email: mmsetyaningsih70@gmail.com
}

\section{Abstract}

Delayed cord clamping leads to the increased level of haematocrite and victocytes which is high risk of hyperbilirubinemia . This study is to determine if there is an effect of timing of cord clamping relating to the incidence of hyperbilirubinemia on newborn, and to create formulating the standard procedures in maternal interventions related to the timing of cord clamping, another objective is preventing interventions of its occurrence when the clamping is performed immediately after birth. Crossectional study was applied design of the research. Population and samples included infants spontaneus by healthy primigravidas. Two trials were included, 20 participants of each received interventions of cord clamping more than equalivalent 1 minute and less than 1 minute followed by bilirubin assessment 48 hours after birth, and analysed by using Linier Regression. There is no significant effect of timing of cord clamping on newborn with regard to hiperbilirubinemia, because the effect of the clamping on bilirubin level reaches up to $68.2 \%$, while the other $31.8 \%$ of the varying levels are affected by other factors. There is a need to conduct other relevant studies aimed to prevent hyperbilirubinemia starting from antenatal to postnatal stage.

Key Words: Jaundice, Newborn, Hyperbilirubinemia, Time of Clamping, Primigravidas

\section{Pendahuluan}

Studi mengenai pemotongan tali pusat masih menjadi kontroversi pada beberapa ahli. Ada beberapa ahli yang menyatakan bahwa tali pusat sebaiknya dipotong dalam waktu lebih dari 15 menit untuk meningkatkan aliran darah sebanyak $21 \%$ pada bayi. Ahli yang lain meyakini bahwa tali pusat sebaiknya segera dipotong dalam waktu beberapa detik supaya bayi cepat beradaptasi dengan kondisi fisiknya sendiri (Forro, 2007). Beberapa studi menunjukkan bahwa pengikatan tali pusat tertunda mengakibatkan darah plasenta mengalir ke neonatus sehingga terjadi peningkatan volume darah sebesar $30 \%$ dan peningkatan $60 \%$ eritrosit. Beberapa studi menunjukkan bahwa pengikatan tali pusat tertunda dapat meningkatkan kadar hematokrit dan viskositas darah secara patologis yang menyebabkan berbagai manifestasi klinis diantaranya hiperbilirubinemia, takikardia dan dan hiperviskositas yang dapat menyebabkan gangguan pada sistem neurologis.

Penelitian di Kanada pada tahun 1972 yang membandingkan transfusi plasenta yang terjadi pada bayi aterm dan prematur yang berhubungan dengan waktu pengikatan tali pusat. Hasil pengukuran volume darah yang dilakukan setelah 5 menit transfusi plasenta tidak berbeda pada bayi aterm dan prematur (terjadi peningkatan volume darah $47 \%$ pada bayi aterm dan $50 \%$ pada bayi prematur). Proporsi transfusi plasenta terbesar terjadi pada menit pertama. Pengikatan tali pusat tertunda memberikan waktu lebih banyak untuk transfer darah dari plasenta kepada bayi. Stripping atau milking tali pusat sebelum pengikatan akan menambah volume darah bayi hingga $20 \%$.

Viskositas darah didefinisikan sebagai kontribusi faktor reologik darah terhadap resistensi aliran darah. Viskositas darah tergantung beberapa faktor, dimana determinan mayornya adalah hematokrit 
darah, viskositas plasma, agregasi dan bentuk sel darah merah, sel darah putih, dan diameter pembuluh darah. Diantara semua faktor, hematokrit adalah determinan terpenting dari viskositas darah, dimana $50 \%$ kenaikan viskositas didasarkan atas kenaikan hematokrit.

Viskositas darah berhubungan proporsional secara langsung dengan hematokrit dan viskositas plasma dan berhubungan terbalik dengan deformabilitas sel darah merah. Viskositas darah dapat diukur secara langsung menggunakan suatu alat yang bernama Wells-Brookfield cone-plate viscometer, tetapi karena ketersediaan alat ini masih terbatas, maka nilai hematokrit dapat digunakan untuk menyatakan vikositas darah. (Berhmen, 2000).

Suatu penelitian di Amerika Serikat pada tahun 1966 menyatakan adanya suatu hubungan konsisten antara hematokrit dan viskositas darah. Hematokrit dari bayi baru lahir sangatlah dipengaruhi oleh waktu pengikatan dan pemotongan umbilikus, dimana penjepitan tali pusat tertunda akan menyebabkan terjadinya transfusi plasenta lebih besar dan berkurangnya volume residu plasenta. Polisitemia didefinisikan sebagai kenaikan kadar hematokrit dan hemoglobin darah vena > 2 SD sesuai usia gestasi bayi. Polisitemia dapat menimbulkan banyak komplikasi seperti hiperviskositas dan hiperbilirubinemia. Polisitemia dipengaruhi oleh berbagai faktor risiko, salah satunya adalah faktor obstetrik yaitu lama pengikatan tali pusat setelah bayi dilahirkan.

Penelitian di Glasgow pada tahun 1993 melaporkan pengikatan tali pusat di bawah introitus $20 \mathrm{~cm}$, yang terlambat 30 detik dapat meningkatkan volume sel darah dan meningkatkan rasio tekanan oksigen arteri-alveoli pada hari pertama. Suatu penelitian di Amerika Serikat terhadap 34 bayi yang dilahiran dengan persalinan normal melaporkan bayi dengan pengikatan tali pusat terlambat memiliki volume darah sekitar $93 \mathrm{~mL} / \mathrm{kg}$ saat usia 72 jam sedangkan pada bayi dengan pengikatan tali pusat dini memiliki volume darah sekitar $82 \mathrm{~mL} / \mathrm{kg}$ sehingga pengikatan tali pusat terlambat dapat meningkatkan kadar Hemoglobin selama satu minggu pertama kelahiran.

Penelitian ini bertujuan untuk membuktikan pengaruh kecepatan penjepitan tali pusat pada bayi baru lahir normal yang dilahirkan secara spontan oleh ibu primigravida normal terhadap kejadian hiperbilirubinemia.

\section{Metode}

Desain penelitian cross sectional study dengan pendekatan observasi. Sampel penelitian adalah bayi baru lahir normal yang dilahirkan secara spontan oleh ibu primigravida normal. Peneliti melakukan observasi waktu penjepitan tali pusat pada saat proses persalinan dan mengelompokkan sampel sesuai waktu yang dibutuhkan untuk melakukan penjepitan tali pusat ke dalam kelompok penjepitan $<1$ menit dan $\geq 1$ menit, hingga masing-masing kelompok memperoleh 20 sampel.

Analisis dilakukan melalui dua tahap, tahap pertama adalah analisis univariabel. Pada analisis ini, variabel penelitian dianalisis secara deskriptif untuk mendapatkan gambaran distribusi frekuensi responden. Selanjutnya dilakukan analisis bivariat untuk mengetahui pengaruh variabel bebas terhadap variabel terikat. Untuk menganalisis pengaruh penjepitan tali pusat bayi baru lahir terhadap kejadian hiperbilirubinemia dengan menggunakan uji regresi logistik dengan derajat kemaknaan $(\alpha)=0,05$.

\section{Hasil dan Pembahasan}

Tabel 5.1 Distribusi Karakteristik Responden Berdasarkan Waktu Pemotongan Tali Pusat

\begin{tabular}{cccc}
\hline No. & $\begin{array}{c}\text { Waktu } \\
\text { Pemotongan } \\
\text { Tali Pusat }\end{array}$ & Frekuensi & $\begin{array}{c}\text { Prosen- } \\
\text { tase }\end{array}$ \\
\hline 1. & $<1$ Menit & 20 & $50 \%$ \\
$2 . \quad \geq 1$ Menit & 20 & $50 \%$ \\
\hline & Jumlah & 40 & $100 \%$ \\
\hline
\end{tabular}

Sumber: Data Primer 
Berdasarkan Tabel 5.1 didapatkan data bahwa masing-masing 20 responden (50\%) yang dilakukan penjepitan tali pusat dengan waktu kurang dari 1 menit dan lebih dari 1 menit

Tabel 5.2 Distribusi Karakteristik Responden Berdasarkan Nilai Bilirubin Total

\begin{tabular}{|c|c|c|c|}
\hline No. & $\begin{array}{c}\text { Nilai } \\
\text { Bilirubin } \\
\text { Total }\end{array}$ & Frekuen-si & $\begin{array}{l}\text { Prosen- } \\
\text { tase }\end{array}$ \\
\hline $\begin{array}{l}1 . \\
2 .\end{array}$ & $\begin{array}{c}\text { Normal } \\
\text { Tidak } \\
\text { Normal } \\
\end{array}$ & $\begin{array}{c}38 \\
2\end{array}$ & $\begin{array}{c}95 \% \\
5 \%\end{array}$ \\
\hline & Jumlah & 40 & $100 \%$ \\
\hline
\end{tabular}

Berdasarkan tabel 5.2 didapatkan data bahwa sejumlah 38 responden $(95 \%)$ dari keseluruhan responden berdasarkan nilai bilirubun total memiliki nilai bilirubin total normal $(\leq 10 \mathrm{mg} \%)$ atau tidak terjadi hiperbilirubin.

Tabel 5.3 Distribusi Karakteristik Responden Berdasarkan Nilai Bilirubin Direct

\begin{tabular}{lccc}
\hline No & $\begin{array}{c}\text { Nilai } \\
\text { Bilirubin } \\
\text { Direct }\end{array}$ & $\begin{array}{c}\text { Frekuen- } \\
\text { si }\end{array}$ & $\begin{array}{c}\text { Prosen- } \\
\text { tase }\end{array}$ \\
\hline 1. & Tidak & 3 & $7.5 \%$ \\
2. & $\begin{array}{c}\text { Normal } \\
\text { Normal }\end{array}$ & 37 & $92.5 \%$ \\
\hline & Jumlah & 40 & $100 \%$ \\
\hline
\end{tabular}

Sumber: Data Primer

Berdasarkan tabel 5.3 didapatkan data bahwa sejumlah 37 responden $(95.2 \%)$ memiliki nilai bilirubin direct normal

Tabel 5.4 Distribusi Karakteristik Responden Berdasarkan Nilai Bilirubin Indirect

\begin{tabular}{|c|c|c|c|}
\hline No & $\begin{array}{l}\text { Nilai Bilirubin } \\
\text { Indirect }\end{array}$ & $\begin{array}{l}\text { Freku- } \\
\text { ensi }\end{array}$ & Prosentase \\
\hline 1. & Normal & 21 & $52.5 \%$ \\
\hline 2. & Tidak Normal & 19 & $47.5 \%$ \\
\hline & Jumlah & 40 & $100 \%$ \\
\hline \multicolumn{4}{|c|}{$\begin{array}{l}\text { Berdasarkan tabel } 5.4 \text { didapatkan } \\
\text { bahwa sejumlah } 21 \text { responden } \\
5 \%) \text { memiliki nilai Bilirubin Indirect } \\
\text { am batas normal }(\leq 9 \mathrm{mg} \%) \text { atau tidak }\end{array}$} \\
\hline
\end{tabular}

Tabel 5.5 Distribusi Karakteristik Nilai Bilirubin Total Responden Berdasarkan Waktu Pemotongan Tali Pusat

\begin{tabular}{|c|c|c|c|c|}
\hline \multirow{3}{*}{$\begin{array}{l}\mathbf{N} \\
\mathbf{0}\end{array}$} & \multirow{3}{*}{$\begin{array}{l}\text { Nilai } \\
\text { Bilirubin } \\
\text { Total }\end{array}$} & \multicolumn{2}{|c|}{$\begin{array}{l}\text { Waktu Pemotongan } \\
\text { Tali Pusat }\end{array}$} & \multirow[b]{2}{*}{ Total } \\
\hline & & $\begin{array}{l}<1 \\
\text { Menit }\end{array}$ & $\geq 1$ Menit & \\
\hline & & n & n & \\
\hline 1 & Normal & 20 & 18 & 38 \\
\hline 2 & Tidak & 0 & 2 & 2 \\
\hline & Jumlah & 20 & 20 & 40 \\
\hline
\end{tabular}

Sumber: Data Primer

Berdasarkan tabel 5.5 menunjukkan bahwa 20 orang responden pada kelompok dengan pemotongan tali pusat $<1$ menit, mempunyai kadar bilirubin normal. Adapun pada kelompok dengan pemotongan tali pusat $\geq 1$ menit, ada sebanyak 18 bayi yang mempunyai kadar bilirubin dengan kategori normal.

Tabel 5.6 Distribusi Karakteristik Nilai Bilirubin Direct Responden Berdasarkan Waktu Pemotongan Tali Pusat

\begin{tabular}{|c|c|c|c|c|}
\hline \multirow{3}{*}{ No } & \multirow{3}{*}{$\begin{array}{l}\text { Nilai } \\
\text { Bilirubin } \\
\text { Direct }\end{array}$} & \multicolumn{2}{|c|}{$\begin{array}{l}\text { Waktu } \\
\text { PemotonganTali } \\
\text { Pusat }\end{array}$} & \multirow[t]{2}{*}{ Total } \\
\hline & & $\begin{array}{l}<1 \\
\text { Menit }\end{array}$ & $\begin{array}{l}\geq 1 \\
\text { Menit }\end{array}$ & \\
\hline & & n & $\mathbf{n}$ & $\mathrm{N}$ \\
\hline 1. & Normal & 19 & 18 & 37 \\
\hline \multirow[t]{2}{*}{2.} & Tidak & 1 & 2 & 3 \\
\hline & Jumlah & 20 & 20 & 40 \\
\hline
\end{tabular}

Berdasarkan tabel 5.6 menunjukkan bahwa pada kelompok pemotongan tali pusat <1 menit, sebanyak 19 bayi yang mempunyai kadar bilirubin normal. Pada kelompok dengan pemotongan tali pusat $\geq 1$ menit, didapatkan sebanyak 18 bayi yang mempunyai kadar bilirubin dengan kategori normal. 
Tabel 5.7 Distribusi Karakteristik Nilai Bilirubin Indirect Responden Berdasarkan Waktu Pemotongan Tali Pusat

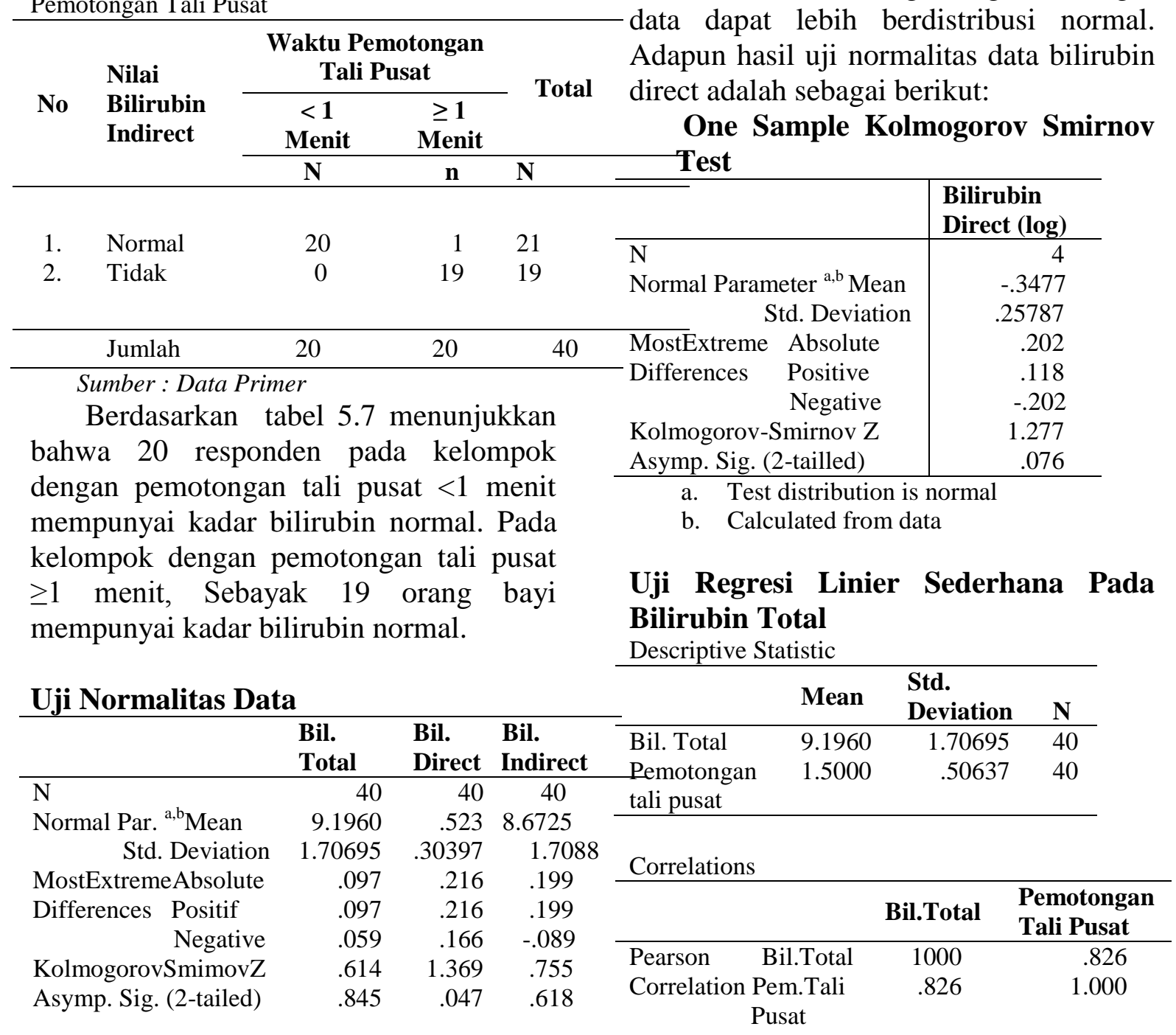

\section{a. Test distribution is Normal \\ b. Calculated from data}

Berdasarkan pengujian normalitas data dengan menggunakan Uji Kolmogorov Smirnov, data bilirubin total dan bilirubin indirect mempunyai nilai signifikansi 0.845 dan 0.618 ( $\mathrm{p}>0.05$ ), sehingga dapat disimpulkan bahwa data bilirubin indirect tersebut menyebar mengikuti sebaran normal. Pengidentifikasi tentang pengaruh waktu pemotongan tali pusat terhadap kadar bilirubin total dapat dilakukan dengan menggunakan uji regresi, karena asumsi kenormalan distribusi data telah terpenuhi. Data bilirubin direct tergolong tidak berdistribusi normal karena mempunyai nilai signifikansi $0.047 \quad(\mathrm{p}<0.05)$. Oleh karena itu, data bilirubin direct dilakukan transformasi data dengan logaritma, agar data dapat lebih berdistribusi normal. Adapun hasil uji normalitas data bilirubin One Sample Kolmogorov Smirnov

Uji Regresi Linier Sederhana Pada

Descriptive Statistic

\begin{tabular}{clrr}
\hline Sig.(1-tailed)Bil.Total & \multicolumn{1}{c}{} & .000 \\
& Pem. Tali Pusat & .000 &. \\
\hline N & Bilirubin total & 40 & 40 \\
& Pem.Tali Pusat & 40 & 40 \\
\hline
\end{tabular}

Variables Entered/Removed

\begin{tabular}{|c|c|c|c|}
\hline Model & $\begin{array}{l}\text { Variables } \\
\text { Entered }\end{array}$ & $\begin{array}{l}\text { Variables } \\
\text { Removed }\end{array}$ & Method \\
\hline 1 & $\begin{array}{l}\text { Pemotongan } \\
\text { Tali Pusat }\end{array}$ & & Enter \\
\hline
\end{tabular}

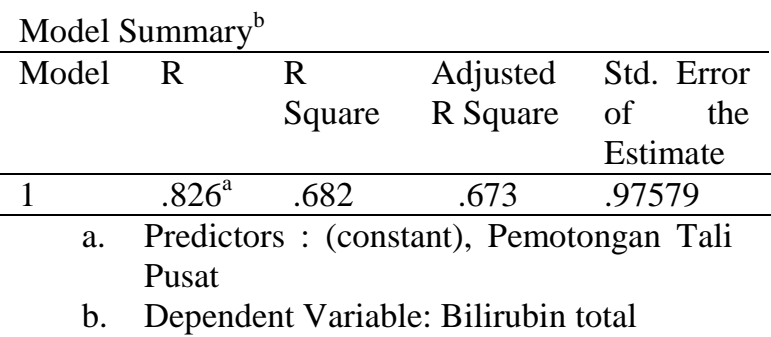




\begin{tabular}{lrrrrr}
\hline Model & $\begin{array}{l}\text { Sum of } \\
\text { Squa-res }\end{array}$ & Df & $\begin{array}{l}\text { Mean } \\
\text { Square }\end{array}$ & F & Sig. \\
\hline Regression & 77.451 & 1 & 77.451 & 81.342 & $.000^{\mathrm{a}}$ \\
Residual & 36.182 & 38 & .952 & & \\
Total & 113.633 & 39 & & & \\
\hline \multicolumn{1}{c}{ a. } & Predictors : & (constant), Pemotongan & Tali \\
& Pusat \\
b. & Dependent variable : Bilirubin total
\end{tabular}

Coefficients $^{\mathrm{a}}$

\begin{tabular}{lccccc}
\hline & $\begin{array}{l}\text { Under- } \\
\text { standized } \\
\text { Codel }\end{array}$ & $\begin{array}{l}\text { Standa } \\
\text { r- } \\
\text { dized } \\
\text { Coeff }\end{array}$ & T & Sig. \\
\cline { 2 - 6 } & B & $\begin{array}{l}\text { Std. } \\
\text { Er- } \\
\text { ror }\end{array}$ & Beta & & \\
\hline 1 & & & & 10.292 & .000 \\
$\begin{array}{l}\text { (constant) } \\
\begin{array}{l}\text { Pem.Tali } \\
\text { Pusat }\end{array}\end{array}$ & 5.022 & .488 & & & \\
\hline
\end{tabular}

Interpretasi :

Berdasarkan hasil uji regresi linier, didapatkan persamaan regresi sebagai berikut:

\begin{tabular}{ll}
\hline Persamaan regresi & R Square \\
\hline $\begin{array}{l}\mathrm{Y}=5.022+2.783 \mathrm{X} \\
\text { (pemotongan tali pusat) }\end{array}$ & $68.2 \%$ \\
\hline $\begin{array}{l}\text { Keterangan : } \\
\mathrm{Y}=\text { Bilirubin total }\end{array}$ \\
$\mathrm{X}=$ Pemotongan tali pusat $(<1$ menit dan $\geq 1$ \\
menit)
\end{tabular}

Hal tersebut dapat diartikan bahwa tanpa mempertimbangkan pengaruh dari kecepatan pemotongan tali pusat pada bayi baru lahir normal $(<1$ menit dan $\geq 1$ menit), maka kadar bilirubin total akan cenderung meningkat secara konstan $5.022 \mathrm{mg} / \mathrm{dL}$ (karena koefisien konstanta bernilai positif). Namun apabila mempertimbangkan pengaruh dari kecepatan pemotongan tali pusat $\geq 1$ menit akan menyebabkan rata-rata kadar bilirubin total mengalami peningkatan hingga $2.783 \mathrm{mg} / \mathrm{dL}$. Berdasarkan hasil uji regresi juga dihasilkan nilai koefisien determinasi (R square $=r^{2}$ ) yang menyatakan besarnya pengaruh kecepatan pemotongan tali pusat pada bayi baru lahir normal terhadap kadar bilirubin total, dalam bentuk presentase, dan presentase

sisanya (1-R Square) ditentukan oleh factor lain. Jadi dapat dikatakan bahwa pengaruh kecepatan pemotongan tali pusat pada bayi baru lahir normal terhadap kadar bilirubin total hingga $68.2 \%$. Terdapat $31.8 \%$ keragaman rata-rata kadar bilirubin total tersebut dipengaruhi oleh factor lain selain dari kecepatan pemotongan tali pusat pada bayi baru lahir normal.

\section{Uji Regresi Linier Sederhana Pada Bilirubin Direct}

Descriptive Statistic

\begin{tabular}{lccc}
\hline & Mean & $\begin{array}{c}\text { Std. } \\
\text { Deviation }\end{array}$ & N \\
\hline Bilirubin direct $(\log )$ & -.3477 & .25787 & 40 \\
PemotonganTali Pusat & 1.5000 & .50637 & 40
\end{tabular}

Correlations

\begin{tabular}{|c|c|c|}
\hline Pearson Correlation & $\begin{array}{l}\text { Bilirubin } \\
\text { Direct } \\
(\log )\end{array}$ & $\begin{array}{l}\text { Pemoton } \\
\text { gan Tali } \\
\text { Pusat }\end{array}$ \\
\hline Pearson Bil.Direct $(\log )$ & 1000 & .156 \\
\hline CorrelationPem.Tali Pusat & .156 & 1.000 \\
\hline Sig. (1-tailed)Bil.Direct(log) & & .168 \\
\hline Pem.TaliPusat & .168 & . \\
\hline \multirow{2}{*}{$\begin{array}{l}\text { Bil.Direct(log) } \\
\text { Pem.Tali Pusat }\end{array}$} & 40 & 40 \\
\hline & 40 & 40 \\
\hline
\end{tabular}

Variables Entered/Removed

\begin{tabular}{llll}
\hline Model & $\begin{array}{l}\text { Variables } \\
\text { Entered }\end{array}$ & $\begin{array}{l}\text { Variables } \\
\text { Removed }\end{array}$ & Method \\
\hline 1 & $\begin{array}{l}\text { Pemotongan } \\
\text { Tali Pusat }\end{array}$ & Enter \\
& All requested variablesented & \\
\hline
\end{tabular}

a. All requested variables entered

b. Dependent variable: bilirubin direct $(\log )$

Model Summary

\begin{tabular}{|c|c|c|c|c|}
\hline Model & $\mathbf{R}$ & $\begin{array}{l}\text { R } \\
\text { Squa } \\
\text { Re }\end{array}$ & $\begin{array}{l}\text { Adjusted } \\
\text { R } \\
\text { Square }\end{array}$ & $\begin{array}{l}\text { Std. } \\
\text { Error of } \\
\text { the } \\
\text { Estimate }\end{array}$ \\
\hline 1 & $.156^{\mathrm{a}}$ & .024 & .001 & .25803 \\
\hline
\end{tabular}




\begin{tabular}{|c|c|c|c|c|c|}
\hline Model & $\begin{array}{l}\text { Sum of } \\
\text { Square } \\
\text { S }\end{array}$ & Df & $\begin{array}{l}\text { Mean } \\
\text { Squar } \\
\text { e }\end{array}$ & $\mathbf{f}$ & Sig. \\
\hline 1 Regression & .063 & 1 & .063 & .9 & $.335^{\mathrm{a}}$ \\
\hline Residual & 2.530 & 38 & .067 & 5 & \\
\hline Total & 2.593 & 39 & & 3 & \\
\hline
\end{tabular}

Coefficients $^{\mathrm{a}}$

\begin{tabular}{lcccccc}
\hline & \multicolumn{2}{c}{$\begin{array}{c}\text { Unstandarized } \\
\text { Coeff }\end{array}$} & $\begin{array}{c}\text { Stadarized } \\
\text { Coeff }\end{array}$ & & \\
\cline { 2 - 4 } \multicolumn{1}{c}{ Model } & B & Etd. & Error & Beta & T & Sig \\
\hline $\begin{array}{l}\text { 1(Const) } \\
\text { Pem. Tali }\end{array}$ & -.467 & .129 & & -3.621 & .001 \\
Pusat & .080 & .082 & .156 & .976 & .335 \\
\hline
\end{tabular}

a. Dependent Variable: Bilirubin direct $(\log )$

Berdasarkan hasil pengujian regresi linier, didapatkan persamaan regresi sebagai berikut:

\begin{tabular}{lc}
\hline Persamaan regresi & R Square \\
\hline $\begin{array}{l}\text { Y=-0.467+0.080X } \\
\text { (Pemotongan tali pusat) }\end{array}$ & $2.4 \%$ \\
\hline
\end{tabular}

\section{Keterangan:}

$\mathrm{Y}=$ bilirubin direct $(\log )$

$\mathrm{X}=$ pemotongan tali pusat $(<1$ menit dan $\geq 1$ menit)

Hal ini berarti tanpa mempertimbangkan pengaruh dari kecepatan pemotongan tali pusat pada bayi baru lahir normal $(<1$ menit dan $\geq 1$ menit), maka kadar bilirubin direct akan cenderung lebih rendah secara konstan $0.467 \mathrm{mg} / \mathrm{dL}$ (karena koefisien konstanta bernilai negatif). Namun apabila mempertimbangkan pengaruh dari kecepatan pemotongan tali pusat pada bayi baru lahir normal dimana pemotongan tali pusat $\geq 1$ menit akan menyebabkan rata-rata kadar bilirubin direct mengalami peningkatan hingga $0.080 \mathrm{mg} / \mathrm{dL}$. Selanjutnya, berdasarkan hasil uji regresi juga menunjukkan nilai koefisien determinasi $\left(\mathrm{R}\right.$ Square $=\mathrm{r}^{2}$ ) yang menyatakan besarnya pengaruh kecepatan pemotongan tali pusat pada bayi baru lahir normal terhadap kadar bilirubin direct, dalam bentuk presentase, dan presentase sisanya (1-R Square) ditentukan oleh factor lain. Jadi dapat dikatakan bahwa pengaruh kecepatan pemotongan tali pusat pada bayi baru lahir normal terhadap kadar bilirubin direct hanya $2.4 \%$, sedangkan $97.6 \%$ dapat dipengaruhi faktor lain.

\section{Uji Regresi Linier Sederhana Pada Bilirubin Indirect}

Descriptive statistics

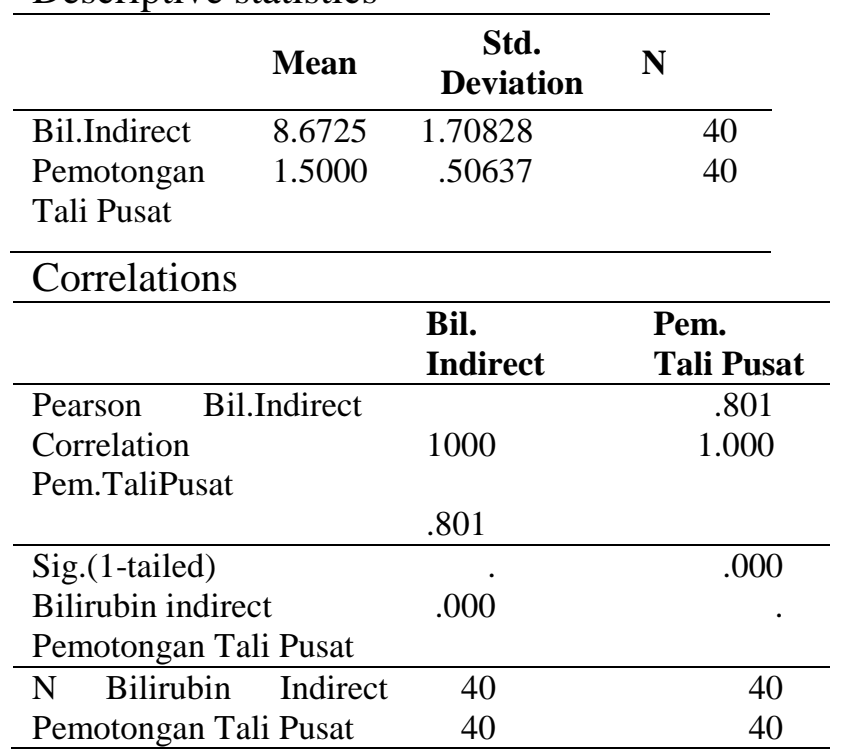

Variables Entered/Removed

\begin{tabular}{llll}
\hline Model & $\begin{array}{l}\text { Variables } \\
\text { Entered }\end{array}$ & $\begin{array}{l}\text { Variables } \\
\text { Removed }\end{array}$ & Method \\
\hline 1 & & Pemotongan & Enter \\
& Tali Pusat & \\
\hline \multicolumn{3}{l}{ a. } & All requested variables entered \\
b. & Dependent variable: bilirubin indirect
\end{tabular}

Model Summary ${ }^{\mathrm{b}}$

\begin{tabular}{|c|c|c|c|c|c|c|}
\hline Model & $\mathbf{R}$ & \multicolumn{2}{|c|}{$\begin{array}{l}\text { R } \\
\text { Square }\end{array}$} & $\begin{array}{l}\text { Adjusted } \\
\text { R Square }\end{array}$ & \multicolumn{2}{|c|}{$\begin{array}{l}\text { Std.Er.of } \\
\text { Estimate }\end{array}$} \\
\hline 1 & .801 & \multicolumn{2}{|c|}{.641} & .632 & \multicolumn{2}{|c|}{1.03691} \\
\hline \multicolumn{7}{|c|}{$\begin{array}{l}\text { a. Predictors: (constant), pemotongan tali pusat } \\
\text { b. Dependent variable: bilirubin indirect }\end{array}$} \\
\hline \multicolumn{2}{|l|}{ Model } & $\begin{array}{l}\text { Sum } \\
\text { of } \\
\text { Squar } \\
\text { es }\end{array}$ & Df & $\begin{array}{l}\text { Mean } \\
\text { Squar } \\
\text { e }\end{array}$ & $\begin{array}{l}\text { F } \\
\text { Sig }\end{array}$ & Sig. \\
\hline \multicolumn{7}{|c|}{1} \\
\hline \multicolumn{2}{|c|}{ Regression } & 72.954 & 1 & 72.954 & 67.853 & $.000^{\mathrm{a}}$ \\
\hline \multicolumn{2}{|c|}{ Residual } & 40.857 & 38 & 1.075 & & \\
\hline \multicolumn{2}{|c|}{ Total } & 113.811 & 39 & & & \\
\hline
\end{tabular}

a. Predictors: (constant), pemotongan tali pusat

b. Dependent variable: bilirubin indirect 
Coefficients $^{\mathrm{a}}$

\begin{tabular}{llllll}
\hline \multirow{2}{*}{ Model } & \multicolumn{2}{l}{$\begin{array}{l}\text { Understan- } \\
\text { dized Coeff }\end{array}$} & $\begin{array}{l}\text { Stand } \\
\text { ar- } \\
\text { dized } \\
\text { Coeff }\end{array}$ & T & Sig. \\
\cline { 2 - 4 } & B & $\begin{array}{l}\text { Std. } \\
\text { Err }\end{array}$ & Beta & & \\
\hline $\begin{array}{l}\text { (constant) } \\
\text { Pem.Tali }\end{array}$ & 4.621 & .518 & & 8.913 & .000 \\
Pusat & 2.701 & .328 & .801 & 8.237 & .000 \\
\hline
\end{tabular}

Dependent variable: bilirubin indirect

Interpretasi:

Berdasarkan hasil pengujian dengan menggunakan analisis regresi linier, dengan hasil persamaan regresi sebagai berikut:

\begin{tabular}{ll}
\hline \multicolumn{1}{c}{ Persamaan regresi } & R Square \\
\hline $\begin{array}{l}\mathrm{Y}=4.621+2.701 \mathrm{X} \\
\text { (pemotongan tali pusat) }\end{array}$ & $64.1 \%$ \\
\hline
\end{tabular}

Keterangan:

$\mathrm{Y}=$ bilirubin indirect

$\mathrm{X}=$ pemotongan tali pusat $(<1$ menit dan $>1$ menit)

Hal ini dapat diartikan bahwa tanpa mempertimbangkan pengaruh dari kecepatan pemotongan tali pusat pada bayi baru lahir normal $(<1$ menit dan $\geq 1$ menit), maka kadar bilirubin indirect akan cenderung meningkat secara konstan $4.621 \mathrm{mg} / \mathrm{dL}$ (karena koefisien konstanta bernilai positif). Namun apabila mempertimbangkan pengaruh dari kecepatan pemotongan tali pusat pada bayi baru lahir normal dimana pemotongan tali pusat $\geq 1$ menit akan menyebabkan rata-rata kadar bilirubin indirect mengalami peningkatan hingga $2.701 \mathrm{mg} / \mathrm{dL}$. Selanjutnya, berdasarkan hasil uji regresi juga menunjukkan nilai koefisien determinasi ( $\mathrm{R}$ Square $=\mathrm{r} 2$ ) yang menyatakan besarnya pengaruh kecepatan pemotongan tali pusat pada bayi baru lahir normal terhadap kadar bilirubin indirect hingga $64.1 \%$. Sedangkan $35.9 \%$ keragaman rata-rata kadar bilirubin indirect tersebut dipengaruhi oleh factor lain selain dari kecepatan pemotongan tali pusat pada bayi baru lahir normal.

\section{Kesimpulan dan Saran}

Dalam penelitian ini didapatkan hasil bahwa tidak terdapat pengaruh yang signifikan antara kecepatan waktu pemotongan tali pusat pada bayi baru lahir normal dengan kejadian hiperbilirubin. Dalam penelitian ini secara khusus juga dapat disimpulkan bahwa perbedaan waktu penjepitan tali pusat yang diberlakukan, tidak memberikan perbedaan yang bermakna pada nilai kadar bilirubin bayi baru lahir normal. Disarankan untuk lebih memperhatikan kondisi ibu sejak masa ante natal, intra natal, dan post natal untuk mencegah terjadinya hiperbilirubin pada bayi baru lahir

Ucapan terima kasih ditujukan kepada:

1. Direktorat P2M Dirjen Dikti yang telah memfasilitasi penelitian berupa pemberian dana.

2. Kopertis Wil.VII yang telah memberikan bimbingan dan kesempatan

3. Direktur RS.Panti Waluya Malang yang telah memberikan ijin dan kesempatan penelitian

4. Direktur AKPER Panti Waluya Malang atas bantuan dan dukungan yang telah diberikan kepada peneliti

5. Ketua LPPM AKPER Panti Waluya Malang atas bantuan administratif dan non administrative yang telah diberikan

6. Teman-teman di AKPER Panti Waluya yang telah memberikan dukungan

Ibu-bu hamil yang telah bersedia menjadi responden dalam penelitian ini.

\section{Daftar Pustaka}

Abalos. (2007). Effect of timing of umbilical cord clamping of term infants on maternal and neonatal outcomes. http://apps.who.int/rhl/pregnancy 
childbirth/childbirth/3rd_stage/cd0 04074_abalose_com/en/.

Didownload tanggal 8 Mei 2013

Behrman, Kliegman, Arvin. (2000). Ilmu Kesehatan Anak. Jakarta: EGC

Bobak, Lowdermilk, Jensen. (2004). Keperawatan Maternitas edisi 4. Jakarta: EGC

Committee on Obstetric Practice . (2007).

Timing of Umbilical Cord Clamping After

Birth.http://www.acog.org/Resourc es\%20And\%20Publications/Comm ittee\%20Opinions/Committee\%20 on\%200bstetric\%20Practice/Timi ng\%20of\%20Umbilical\%20Cord\% 20Clamping\%20After\%20Birth.as px. Didownload tanggal 8 Mei 2013

Danim Sudarwan. (2003). Riset Keperawatan. Jakarta: EGC

Forro, Chinmayo. (2007). Childbirth with Love.

http://www.childbirthwithlove.com /controversy.html. Diakses tangal 23 April 2013

Hamidi, Majid dan Masoomeh Alidoosti. (2012). The relationship between Umbilical cord Alpha Fetoprotein and Hyperbilirubinemia in Third day

http://journal.skums.ac.ir/browse.p hp?a_id=1184\&sid=1\&slc_lang=e

n. Didownload tanggal 8 Mei 2013

Klaus, Fanaroff. (1998). Penatalaksanaan Neonatus Resiko Tinggi. Jakarta: EGC

Kosim Sholeh,Yunanto Ari, Dewi Rizalya, Sarosa Irawan, Usman. (2010). Buku Ajar Neonatologi. Jakarta: Badan Penerbit IDAI
Kristiyanasari. (2009). Neonatus \& Asuhan Keperawatan Anak. Yogyakarta: Nuha Offset.

Lowdermilk, Bobak, Jensen. (1999). Maternity Nursing $5^{\text {th }}$ edition. Missouri: Mosby Year Book

Margaretha. (2010). Kuning Pada Bayi.Keluarga.com/cibubur/kuning padabayi. Diakses tanggal 19 April 2013 jam 11.25 WIB.

Notoatmodjo,Soekidjo. (2010). Metodologi Penelitian Kesehatan. Edisi revisi. Rineka Cipta: Jakarta

Patton, 2007. Efek Pemberian Zinc Per Oral Terhadap Kejadian Hiperbilirubinemia Pada Bayi Baru Lahir Sehat Cukup Bulan. http://rshs.or.id/e-jurnal/article/57. didownload tanggal 7 Mei 2013

Setiadi (2007). Konsep dan Penulisan Riset Keperawatan. Yogyakarta: Penerbit Graha Ilmu 